\title{
Factors associated with transactional sex among a cohort of gay, bisexual, and other men who have sex with men in Vancouver, Canada
}

Heather L. Armstrong ${ }^{A}, *(D)$, Jordan M. Sang ${ }^{B}$, Ales Skala ${ }^{C}$, Lu Wang ${ }^{B}$, Julia Zhu ${ }^{B}$, Nathan J. Lachowsky ${ }^{B, D}$, Kiffer G. Card ${ }^{D}$ (D), Cecilia Benoit ${ }^{D}$, Gbolahan Olarewaju ${ }^{B, C}$, Robert S. Hogg, ${ }^{B, E}$, David M. Moore ${ }^{B, C}$ and Eric A. Roth ${ }^{\mathrm{D}}$

For full list of author affiliations and declarations see end of paper

*Correspondence to:

Heather L. Armstrong

University of Southampton, University Road,

Southampton SOI7 IBJ, UK

Email: h.armstrong@soton.ac.uk

Handling Editor:

Jami Leichliter

\begin{abstract}
Background. Gay, bisexual, and other men who have sex with men (GBM) who engage in transactional sex (sex in exchange for drugs, money, or goods) experience increased risk of sexually transmitted infections (STI), including HIV. This study explored additional psychosocial and health-related factors associated with transactional sex among GBM. Methods. Respondent-driven sampling was used to recruit GBM in Vancouver, Canada, from 2012 to 20I5, with follow up every 6 months until July 2019. We examined factors associated with transactional sex using multivariable three-level mixed-effects modelling. Results. Among 698 GBM, 22.1\% reported ever receiving drugs, money, or goods for sex. Transactional sex was more likely to be reported by GBM who were younger ( $<30$ years) and who had lower incomes, less education, and insecure housing. GBM reporting transactional sex were more likely to report substance use (i.e. crystal methamphetamine, poppers, GHB, and non-steroid injection drugs) and higher risk sexual behaviours (i.e. more sex partners, sex party attendance, and condomless anal sex with serodifferent or unknown HIV status partners); however, they were no more likely to be living with HIV or to report a recent bacterial STI diagnosis. GBM who reported higher loneliness, anxiety, and cognitive escape were also more likely to report transactional sex. Conclusions. More than one-fifth of GBM in Vancouver reported transactional sex and those who did were more likely to also experience psychosocial stressors, increased substance use, and higher risk sexual behaviours. Programs which consider the interconnections of personal, social, and structural challenges faced by GBM engaging in transactional sex are necessary to support improved mental, physical, and sexual health for these men.
\end{abstract}

Keywords: HIV, mental health, MSM, sexual behaviours, sex work, STI, substance use, syndemic factors, transactional sex.

\section{Introduction}

Received: 28 July 2021

Accepted: 18 October 2021

Published: 30 November 2021

Cite this:

Armstrong HL et al. (202I)

Sexual Health

doi: $10.107|/ S H 21| 28$

(C) 2021 The Author(s) (or their employer(s)). Published by CSIRO Publishing.
Gay, bisexual, and other men who have sex with men (GBM) are disproportionally affected by human immunodeficiency virus (HIV) and other sexually transmitted infections (STI). ${ }^{1,2}$ In 2019, GBM in Canada represented $43.1 \%$ of newly diagnosed HIV cases, the largest of any exposure group, ${ }^{2}$ and within the GBM community of Vancouver, Canada, the estimated prevalence of HIV is $23.4 \% .{ }^{3}$ Individuals who engage in transactional sex, commonly defined as the trading of money, goods, or drugs for sexual services, ${ }^{4}$ are also at increased risk of HIV and STI transmission. ${ }^{5}$ Many factors, including sexual behaviour and substance use, as well as psychosocial social factors such as loneliness, community depression, which may contribute to increased risk of HIV and other STIs among GBM, may also be associated syndemically with participating in transactional sex. connectedness, sensation seeking, cognitive escape, and symptoms of anxiety and 
Although transactional sex is often thought of as escort work or prostitution, other exchange relationships also exist (e.g. sugar daddies/babies) and these can be casual or ongoing. ${ }^{6}$ It is estimated that approximately $20-25 \%$ of adults engaged in sex work are men ${ }^{7}$ and, although the majority of their clients also identify as men, research shows most of these clients do not identify as gay or bisexual and many have cisgender women as their regular sex partners. $^{8}$ Further contributing to the challenges of studying and understanding transactional sex among GBM are high levels of stigma, ${ }^{9}$ which consequently mean that GBM who engage in transactional sex rarely identify as sex workers. ${ }^{8}$ Given these challenges, for the present study, we consider transactional sex as an umbrella term that includes all manner of formal and informal arrangements, and we employ a behavioural definition of having received, or having received and given, any type of goods, drugs, or money in exchange for sex.

Among GBM, several studies have shown that there are multiple interrelated factors, such as social inequities, substance use, mental health (e.g. anxiety and depression), psychosocial factors (e.g. loneliness, cognitive escape, sensation seeking), and behavioural HIV and STI risk, which are associated with transactional sex. ${ }^{10-15}$ In a large, multisite US study of 8411 GBM, 7\% reported transactional sex and those who did so were more likely to identify as Black, be living in poverty, use substances, report condomless anal sex (CAS) with multiple partners, and be living with HIV (both aware and unaware of their status). ${ }^{14}$ Likewise, in a longitudinal study of 722 US GBM living with HIV, 8\% reported recent transactional sex, and results from this study indicated that transactional sex was associated with Black (vs White) race, younger age, lower income, and increased levels of intimate partner violence, substance use, and depression. ${ }^{15}$ Taken together, results from these studies show that there are multiple, overlapping epidemics, which work together syndemically to increase vulnerability to each concurrent negative health outcome for GBM and, as such, are best considered within a syndemic framework. Further, it has been shown that the more syndemic factors GBM had, the more likely they were to also report recent transactional sex. ${ }^{10,15}$ As such, research among GBM needs to consider a variety of psychosocial, behavioural, and physical and mental health factors to develop a better understanding of the true scope of transactional sex.

When considering transactional sex among GBM, most research has looked at associations to HIV risk. In a scoping literature review of HIV and cisgender men who engage in sex work, including studies from countries around the world, Baral et al. identified multiple risk factors and barriers that may increase HIV risk including stigma, criminalisation of sex work, reporting older partners, sex in combination with substance use, and less access to preventative and care services compared to GBM who do not engage in sex work. ${ }^{8}$ However, generalisability of previous studies is limited due to geographic variability of HIV prevalence among GBM in general, and among GBM who engage in transactional sex in particular. ${ }^{5}$

Within the Canadian context, the majority of research on GBM sex work has also focused on HIV risk. For example, in a previous study of GBM aged 18-30 years, living in Vancouver between 1995 and 1999, 16\% (125/761) reported engaging in sex work in the previous year and among these, the prevalence of HIV was previously $7.3 \% .{ }^{16}$ However, most of this work is dated and more current studies are needed. ${ }^{16,17}$ One exception is a 2018 study from Vancouver in which Argento et al. used qualitative interviews with GBM and transgender women who buy or sell sex to examine the role of the online environment in relation to transactional sex. ${ }^{18}$ The authors found that although the loss of physical environments for sex work led to social isolation and loss of social supports, the online environment for transactional sex provided greater control, negotiation capacity, and increased security. ${ }^{18}$

Given the need for more recent research to better understand transactional sex work among GBM within Canada, the current study aimed to describe characteristics of GBM who engage in transactional sex in Vancouver, from 2012 to 2019. We also sought to explore how sexual behaviours, substance use, psychosocial factors, and specific HIV prevention strategies were associated with engagement in transactional sex. Understanding which factors are associated with transactional sex may help target HIV and STI prevention and treatment programs for this marginalised population and improve their overall health and wellbeing. We hypothesise that GBM who report transactional sex will experience greater psychosocial stressors, increased substance use, and higher risk sexual behaviour than GBM who do not; however, we also hypothesise they will also be less likely to report use of HIV prevention strategies.

\section{Methods}

Participants were part of the Momentum Health Study, a longitudinal cohort study of GBM in Vancouver, Canada. Recruitment used respondent-driven sampling (RDS), a sampling method used to reach harder-to-reach populations based off chain-referral sampling. ${ }^{19}$ Sampling is started by selecting 'seeds' who meet eligibility criteria from the target population through community groups or through digital social-sexual networking services. Study participants were trained in peer-recruitment by study staff and given six vouchers to recruit participants in their networks. Eligibility criteria were that participants had to identify as men (including trans men), be aged at least 16 years, reside in Metro Vancouver, report having sex with another man in the past 6 months, and be able to complete the questionnaire in English. Additionally, participants must have either been 
selected as seeds or have received a valid study voucher from another participant. Participants received a CA $\$ 50$ honorarium for participating at each study visit and an additional CA $\$ 10$ for each enrolling participant they recruited using their study vouchers. Payment could be taken in cash or equivalent prize draw tickets. Recruitment occurred between February 2012 and February 2015 and follow-up visits occurred every 6 months until July 2019. HIV-negative participants completed a maximum of eight study visits, whereas participants living with HIV did not have an upper limit for number of visits. At every study visit, participants completed a computer-assisted self-interview (CASI), which included a variety of psychosocial, behavioural, and healthrelated measures, and a nurse's study visit, which included HIV and STI testing. Full methodology has been published elsewhere. ${ }^{3}$ Ethics approval was received from the research ethics boards of the University of British Columbia, Simon Fraser University, and the University of Victoria, and all participants provided informed consent.

\section{Measures}

\section{Outcome measure}

Transactional sex was identified through a series of questions which asked about recent (past 6 months) transactional sex through receiving and giving drugs, money, or goods for sex (e.g. 'Have you received money in exchange for sex?'; 'Have you given drugs in exchange for sex?') with response options: no; yes, in the past 6 months; and yes, but not in the past 6 months. Participants were also asked to indicate if they had received money from 'escort work or sex work' in the past 6 months. As only five participants reported only giving drugs, money, or goods for sex, these were removed from the analysis. Remaining responses were dichotomised into 'Yes', if participants indicated having 'received' or 'received and given' something for sex in the past 6 months, or if they indicated escort or sex work in the past 6 months, and 'No', if participants indicated 'no' or 'yes, but not in the past 6 months'.

\section{Sexual behaviours}

We asked participants to report the number of male and female sex partners they had had in the past 6 months and their preferred anal sex position (top, bottom, versatile, prefer no anal sex). We assessed online sexual behaviours such as recent (past 6 months) use of chat lines, phonebased apps, and websites to seek sex. We also assessed additional recent (past 6 months) sexual behaviours including sex party attendance (defined as an event where four or more people get together for sex, including darkroom and blackout events), fisting, using sex toys with partners, engaging in watersports, and condomless anal sex with a serodifferent or unknown HIV-status partner. We also asked participants to indicate which of the following strategies they use to prevent themselves or their partners from getting HIV (participants could indicate more than one response): always using condoms for anal sex, being the top (for HIV-negative participants) or bottom (for participants living with HIV) for anal sex (referred to as seropositioning), having sex which doesn't include anal sex, having sex without condoms only with guys I know are HIVnegative (for HIV-negative participants) or HIV-positive (for participants living with HIV) (referred to as serosorting), having sex without condoms with HIV-positive guys who have low viral loads or are on HIV treatment (for HIV-negative participants) or having sex without condoms if my viral load is low or I'm on HIV treatment (for participants living with HIV) (referred to as viral load sorting), not letting my partners cum inside me (for HIVnegative participants) or not cumming inside my sex partners (for particpants living with HIV) (referred to as withdrawal), and asking sex partners about their HIV status before sex. We also asked participants how often they disclose their own HIV status prior to sex.

\section{Community connectedness}

Community connectedness measured attendance at pride parades in the past year, and attendance at gay bars and gay-specific groups in the past 6 months. Responses for each question were dichotomised: Yes and No, based on participant self-report.

\section{Substance use}

We assessed a variety of substances used in the past 6 months including erectile dysfunction drugs (EDD) (with prescription and without prescription), crystal methamphetamine, poppers, ecstasy, gamma-hydroxybutyric acid (GHB), ketamine, cocaine, heroin, morphine (without prescription), and non-steroid injection drugs. We also included the Alcohol Use Disorder Test (AUDIT), which measures problematic alcohol use in the past 12 months. We dichotomised scores by low to medium risk (scores $<16$ ) and harmful to possible dependence risk (scores $\geq 16$ ). ${ }^{20}$

\section{Psychosocial measures}

Our psychosocial measures include the Sexual Sensation Seeking Scale (11 items, four-point Likert scale response, $\alpha=0.73),{ }^{21}$ the Cognitive Escape Scale (12 items, fourpoint Likert scale response, $\alpha=0.90)^{22}$ and the Loneliness Scale (six items, five-point Likert scale response, $\alpha=0.77){ }^{23}$ We also included the Hospital Anxiety and Depression Scale (HADS) (14 items, four-point Likert scale response, $\alpha=0.84$ for anxiety, and $\alpha=0.78$ for depression) to measure anxious and depressive symptomology. ${ }^{24}$

\section{Sociodemographic measures}

Our sociodemographic measures included age, income, ethnicity, education, sexual identity, relationship status, housing arrangement, student status, HIV serostatus, and 
whether the participant had any STI diagnoses in the past 6 months.

\section{Analysis}

We used the overall transactional sex variable as the outcome variable in univariable and multivariable models to examine factors associated with reporting transactional sex over the study period. We first conducted univariable generalised linear mixed models to assess the probability of reporting transactional sex. Variables with $P<0.20$ at the univariable level were then tested in multivariable threelevel (RDS chain: participant: visit) mixed-effects logistic regression modelling. Level-1 units were visit-level observations, level-2 clusters were at the participant-level, and level-3 clusters were at RDS chains. A backward selection procedure based on the Akaike Information Criterion (AIC) and minimisation of Type-III $P$-values ${ }^{25}$ was used to determine the final model. All analyses were conducted using SAS v9.4 (SAS Institute Inc., Cary, NC, USA).

\section{Results}

Overall, 698 GBM consented to the longitudinal cohort study and responded to questions on transactional sex. Of these, 154 (22.1\%) reported receiving or both receiving and giving money, drugs, or other goods for sex (past 6 months), or having received money for escort or sex work in the past 6 months, at any visit over the study period. Five participants who reported only giving money, goods, or drugs in exchange for sex (past 6 months) were removed from subsequent analyses. Thus, 693 participants completed 4200 visits, and among those with two or more study visits $(n=581 / 693)$, the median follow-up time was 3.5 years $(\mathrm{Q} 1, \mathrm{Q} 3=3.1,3.8)$.

Among our sample, the median age at baseline was 33 years $(\mathrm{Q} 1, \mathrm{Q} 3=26,47)$; the most reported sexual identity was gay $(86.3 \%)$ and the most reported race/ethnicity was white $(75.4 \%)$. Twenty-eight percent of participants were living with HIV, and the median number of male sex partners reported (past 6 months) was five (Q1, Q3 $=3,15) .39 .4 \%$ of participants reported engaging in condomless anal sex (CAS) with a HIV serodifferent or unknown HIV status partner (past 6 months). Full baseline demographics and univariable results are presented in Table 1.

In univariable analyses, GBM living with HIV were more likely to report transactional sex than HIV-negative GBM (OR $=2.44,95 \%$ CI: $1.17,5.08$ ), as were GBM who scored in the harmful or possible dependence range on the AUDIT scale $(\mathrm{OR}=1.85,95 \%$ CI: $1.07,3.19)$, and those who reported recent (past 6 month) diagnosis of gonorrhoea, chlamydia, or syphilis (OR $=2.90,95 \%$ CI: $1.57,5.37$ ). However, after consideration of additional factors in multivariable models, these associations were no longer significant (described below). Further, with respect to HIV prevention strategies, in univariable analysis, there was no difference in likelihood to report always using condoms, anal sex avoidance, asking the HIV status of sex partners, or serosorting between GBM who reported transactional sex and those who did not. In univariable analysis, transactional sex was associated with sero-positioning (OR $=1.62,95 \%$ CI: 1.06, 2.48), viral load sorting ( $\mathrm{OR}=2.13,95 \% \mathrm{CI}: 1.39,3.26)$, and withdrawal prior to ejaculation ( $\mathrm{OR}=2.41,95 \% \mathrm{CI}$ : $1.55,3.76$ ), but only withdrawal remained significantly associated with transactional sex in the final multivariable model (see below).

Multivariable analysis found increased odds of transactional sex were associated with identifying as bisexual or 'other' (vs gay; aOR $=2.38,95 \%$ CI: 1.21, 4.69), Indigenous ethnicity (vs white; $\mathrm{aOR}=5.27,95 \% \mathrm{CI}$ : 1.34 , 20.80), having more recent (past 6 months) male (aOR $=1.01,95 \%$ CI: $1.005,1.02)$ or female sex partners $(\mathrm{aOR}=1.95,95 \% \mathrm{CI}: 1.35,2.81)$, using internet sites to find sex partners (past 6 months; aOR $=3.26,95 \%$ CI: 1.77 , 6.00 ), and sex party attendance in the past 6 month (aOR $=3.65,95 \%$ CI: $2.14,6.22$ ). Men who reported more CAS with serodifferent or unknown HIV status partners were also more likely to report transactional sex $(\mathrm{aOR}=1.83,95 \%$ CI: $1.03,3.26)$ as were those who reported using withdrawal as an HIV prevention strategy (aOR $=1.79,95 \%$ CI: $1.003,3.20$ ). Substance use (past 6 months) was also associated with increased odds of transactional sex, specifically crystal methamphetamine (aOR $=4.57,95 \%$ CI: 223, 9.39), poppers $(\mathrm{aOR}=2.53,95 \%$ CI: $1.39,4.60)$, gamma-hydroxybutyric acid $(\mathrm{aOR}=2.14$, 95\% CI: 1.15, 4.00), and non-steroid injection drug use (aOR $=3.26,95 \%$ CI: $1.15,9.29)$. Transactional sex was also more likely among those with higher sexual escape motivation $(\mathrm{aOR}=1.06,95 \%$ CI: 1.01, 1.10), higher loneliness $(\mathrm{aOR}=1.19,95 \% \mathrm{CI}: 1.02,1.39)$, and higher current symptoms of anxiety (aOR $=1.08,95 \%$ CI: $1.001,1.17)$.

Decreased odds of transactional sex were associated with older age (30-44 vs $<30$ years: $\mathrm{aOR}=0.27,95 \%$ CI: 0.13 , 0.54 ; $\geq 45$ vs $<30$ years: $\mathrm{aOR}=0.09,95 \%$ CI: $0.03,0.22$ ), annual income $>\$ 30000 \mathrm{CAD}$ (aOR $=0.56,95 \%$ CI: 0.32 , 0.99), having post-secondary education ( $\mathrm{aOR}=0.30,95 \%$ CI: $0.13,0.70)$, and having stable housing $(\mathrm{aOR}=0.39$, 95\% CI: 0.19, 0.82). GBM who reported greater depressive symptomology were also less likely to report transactional sex $(\mathrm{aOR}=0.89,95 \%$ CI: 0.81, 0.97). Full results can be found in Table 2.

\section{Discussion}

Among a community-based sample of GBM in Vancouver, $22.1 \%$ reported recent (past 6 months) transactional sex over the study period from 2012 to 2019 . We found that those who engaged in transactional sex (i.e. those who reported receiving or both receiving and giving money, 
Table I. Baseline participant demographics and univariable generalised linear mixed models for engaging in transactional sex (past 6 months).

\begin{tabular}{|c|c|c|c|c|c|c|}
\hline & \multicolumn{2}{|c|}{$\begin{array}{l}\text { Transactional } \\
\operatorname{sex}(n=103)\end{array}$} & \multicolumn{2}{|c|}{$\begin{array}{l}\text { No transactional } \\
\operatorname{sex}(n=576)\end{array}$} & \multicolumn{2}{|c|}{$\begin{array}{l}\text { Univariable: transactional sex } \\
\text { vs no transactional sex } \\
(n=693)\end{array}$} \\
\hline & $n$ & $\%$ & $n$ & $\%$ & OR & $95 \% \mathrm{Cl}$ \\
\hline \multicolumn{7}{|l|}{ Demographic variables } \\
\hline \multicolumn{7}{|l|}{ Age (years) } \\
\hline$<30$ & 42 & 40.8 & 214 & 37.2 & Ref & \\
\hline $30-44$ & 38 & 36.9 & 186 & 32.3 & 0.55 & $0.29,1.06$ \\
\hline$\geq 45$ & 23 & 22.3 & 176 & 30.6 & 0.28 & $0.14,0.57$ \\
\hline \multicolumn{7}{|l|}{ Income (CAD) } \\
\hline$<\$ 30000$ & 77 & 74.8 & 340 & 59.0 & Ref & \\
\hline$\geq \$ 30000$ & 26 & 25.2 & 236 & 41.0 & 0.45 & $0.28,0.73$ \\
\hline \multicolumn{7}{|l|}{ Ethnicity } \\
\hline White & 74 & 71.8 & 438 & 76.0 & Ref & \\
\hline Asian & 6 & 5.8 & 62 & 10.8 & 0.25 & $0.09,0.68$ \\
\hline Indigenous & 16 & 15.5 & 24 & 4.2 & 8.90 & $2.27,34.91$ \\
\hline Latino/Other & 7 & 6.8 & 52 & 9.0 & 1.10 & $0.36,3.35$ \\
\hline \multicolumn{7}{|l|}{ Education } \\
\hline$\leq$ High school & 41 & 39.8 & 100 & 17.4 & Ref & \\
\hline$>$ High school & 62 & 60.2 & 476 & 82.6 & 0.15 & $0.07,0.35$ \\
\hline \multicolumn{7}{|l|}{ Sexual identity } \\
\hline Gay & 76 & 73.8 & 510 & 88.5 & Ref & \\
\hline Bisexual/other & 27 & 26.2 & 66 & 11.5 & 3.95 & $2.18,7.15$ \\
\hline \multicolumn{7}{|l|}{ HIV status } \\
\hline HIV-negative & 58 & 56.3 & 431 & 74.8 & Ref & \\
\hline HIV-positive & 45 & 43.7 & 145 & 25.2 & 2.44 & I. $17,5.08$ \\
\hline Any STI diagnoses $(p 6 m)^{A}$ & 20 & 19.8 & 37 & 6.7 & 2.90 & $\mathrm{I} .57,5.37$ \\
\hline \multicolumn{7}{|l|}{ Relationship status } \\
\hline In a relationship & 26 & 25.2 & 242 & 42.0 & Ref & \\
\hline Single & 77 & 74.8 & 334 & 58.0 & 2.36 & I.47, 3.80 \\
\hline Stable housing ${ }^{A}$ & 71 & 68.9 & 525 & 92.4 & 0.20 & $0.11,0.39$ \\
\hline Currently a student ${ }^{A}$ & 12 & 11.7 & 127 & 22.0 & 0.47 & $0.23,0.97$ \\
\hline Attended last pride parade ${ }^{A}$ & 61 & 59.2 & 368 & 63.9 & 0.72 & $0.51,1.02$ \\
\hline Attended gay bars $(p 6 m)^{A}$ & 73 & 70.9 & 475 & 82.5 & 1.43 & $0.86,2.37$ \\
\hline Attend gay-specific groups $(p 6 m)^{A}$ & 40 & 38.8 & 224 & 38.9 & 1.70 & I.19, 2.43 \\
\hline \multicolumn{7}{|l|}{ Sexual behaviours (p6m) } \\
\hline Used chat lines to seek sex ${ }^{A}$ & 28 & 27.2 & 55 & 9.5 & 5.60 & $2.49,12.58$ \\
\hline Used apps to seek sex ${ }^{A}$ & 65 & 63.1 & 319 & 55.4 & 2.52 & $1.65,3.84$ \\
\hline Used websites to seek sex ${ }^{A}$ & 86 & 83.5 & 349 & 60.6 & 7.49 & $4.39,12.79$ \\
\hline Attended sex parties ${ }^{A}$ & 54 & 52.4 & 124 & 21.5 & 8.17 & $5.27,12.67$ \\
\hline Fisting ${ }^{A}$ & 26 & 25.2 & 51 & 8.9 & 5.82 & $3.07,11.06$ \\
\hline Sex toys ${ }^{A}$ & 45 & 43.7 & 153 & 26.6 & 3.74 & $2.53,5.54$ \\
\hline Watersports ${ }^{A}$ & 24 & 23.3 & 74 & 12.8 & 3.92 & $2.26,6.80$ \\
\hline CAS with serodifferent/unknown partner ${ }^{A}$ & 60 & 58.8 & 202 & 35.9 & 4.72 & $2.91,7.65$ \\
\hline
\end{tabular}


Table I. (Continued).

\begin{tabular}{|c|c|c|c|c|c|c|c|}
\hline & \multicolumn{2}{|c|}{$\begin{array}{l}\text { Transactional } \\
\operatorname{sex}(n=103)\end{array}$} & \multicolumn{2}{|c|}{$\begin{array}{l}\text { No transactional } \\
\operatorname{sex}(n=576)\end{array}$} & & \multicolumn{2}{|c|}{$\begin{array}{l}\text { Univariable: transactional sex } \\
\text { vs no transactional sex } \\
(n=693)\end{array}$} \\
\hline & $n$ & $\%$ & $n$ & $\%$ & & OR & $95 \% \mathrm{Cl}$ \\
\hline \multicolumn{8}{|l|}{ Anal sex preference } \\
\hline Bottom & 28 & 27.2 & 202 & 35.1 & & Ref & \\
\hline Versatile & 38 & 36.9 & 146 & 25.3 & & 1.50 & $0.86,2.61$ \\
\hline Top & 34 & 33.0 & 202 & 35.1 & & 0.94 & $0.48,1.82$ \\
\hline No anal & 3 & 2.9 & 26 & 4.5 & & 0.29 & $0.10,0.83$ \\
\hline \multicolumn{8}{|l|}{ HIV prevention strategies (p6m) } \\
\hline Always using condoms ${ }^{A}$ & 44 & 42.7 & 324 & 56.5 & & 0.80 & $0.5 \mathrm{I}, \mathrm{I} .24$ \\
\hline Sero-positioning ${ }^{A}$ & 34 & 33.0 & 163 & 28.4 & & 1.62 & $1.06,2.48$ \\
\hline No anal sex ${ }^{A}$ & 42 & 40.8 & 275 & 48.0 & & 1.11 & $0.76,1.61$ \\
\hline Sero-sorting ${ }^{A}$ & 46 & 44.7 & 235 & 41.0 & & 1.29 & $0.88,1.88$ \\
\hline Viral load sorting ${ }^{\mathrm{A}}$ & 28 & 27.2 & 100 & 17.5 & & 2.13 & $1.39,3.26$ \\
\hline Withdrawal ${ }^{\mathrm{A}}$ & 33 & 32.0 & 166 & 29.0 & & 2.41 & $1.55,3.76$ \\
\hline Asking HIV status of sex partners ${ }^{A}$ & 59 & 57.3 & 344 & 60.0 & & 0.98 & $0.69,1.39$ \\
\hline \multicolumn{8}{|c|}{ How often do you disclose your HIV status to your male sex partners } \\
\hline$<50 \%$ & 14 & 13.6 & 72 & 12.5 & & Ref & \\
\hline$\geq 50 \%$ & 59 & 57.3 & 295 & 51.2 & & 1.95 & $1.19,3.21$ \\
\hline Only when asked & 30 & 29.1 & 209 & 36.3 & & 1.69 & I.0I, 2.82 \\
\hline \multicolumn{8}{|l|}{ Substance use $(p 6 m)$} \\
\hline EDDs, no prescription ${ }^{A}$ & 36 & 35.0 & 64 & II.I & & 6.51 & $3.68,11.53$ \\
\hline EDDs, prescription ${ }^{A}$ & 20 & 19.4 & 71 & 12.3 & & 2.24 & $\mathrm{I} .25,4.00$ \\
\hline Crystal methamphetamine ${ }^{\mathrm{A}}$ & 61 & 59.2 & 73 & 12.7 & & 28.94 & $15.53,53.92$ \\
\hline Poppers ${ }^{A}$ & 60 & 58.3 & 202 & 35.1 & & 6.93 & $4.17,11.51$ \\
\hline Ecstasy ${ }^{\mathrm{A}}$ & 46 & 44.7 & 128 & 22.2 & & 4.81 & $3.02,7.64$ \\
\hline Gamma-hydroxybutyric acid ${ }^{A}$ & 48 & 46.6 & 83 & 14.4 & & 12.63 & $7.21,22.13$ \\
\hline Ketamine $^{A}$ & 33 & 32.0 & 64 & II.I & & 7.84 & $4.53,13.59$ \\
\hline Cocaine $^{A}$ & 45 & 43.7 & 132 & 22.9 & & 4.21 & $2.67,6.66$ \\
\hline Speed $^{A}$ & 16 & 15.5 & 22 & 3.8 & & 9.12 & $3.92,21.20$ \\
\hline Heroin $^{A}$ & 14 & 13.6 & 9 & 1.6 & & 14.69 & $3.20,67.49$ \\
\hline Morphine, no prescription ${ }^{A}$ & 6 & 5.8 & 0 & 0 & & 6.35 & $2.19,18.36$ \\
\hline Non-steroid injection drugs ${ }^{A}$ & 30 & 29.1 & 14 & 2.4 & & 13.47 & $5.59,32.44$ \\
\hline \multicolumn{8}{|l|}{ AUDIT score $(p / 2 m)$} \\
\hline Low/medium & 77 & 77.8 & 504 & 87.7 & & Ref & \\
\hline \multirow[t]{2}{*}{ Harmful/dependence } & 22 & 22.2 & 71 & 12.3 & & 3.10 & $1.55,6.20$ \\
\hline & & QI-Q3 & Median & & QI-Q3 & OR & $95 \% \mathrm{Cl}$ \\
\hline \multicolumn{8}{|l|}{ Continuous psychosocial variables } \\
\hline Sexual Sensations Scale $(\alpha=0.73)$ & & $30-37$ & 30 & & $28-34$ & 1.25 & $1.16,1.35$ \\
\hline Cognitive escape scale $(\alpha=0.90)$ & & $29-36$ & 28 & & $24-32$ & 1.13 & $1.09,1.17$ \\
\hline Loneliness scale $(\alpha=0.77)$ & & $2-5$ & 2 & & $1-4$ & 1.31 & I. $18,1.47$ \\
\hline HADS anxiety $(\alpha=0.84)$ & & $7-11$ & 7 & & $5-10$ & 1.14 & $1.09,1.21$ \\
\hline HADS depression $(\alpha=0.78)$ & & $3-8$ & 3 & & $1-6$ & 1.10 & $1.03,1.17$ \\
\hline
\end{tabular}


Table I. (Continued).

\begin{tabular}{|c|c|c|c|c|c|c|}
\hline & Median & QI-Q3 & Median & QI-Q3 & OR & $95 \% \mathrm{Cl}$ \\
\hline \multicolumn{7}{|c|}{ Continuous sexual behaviour variables } \\
\hline No. male sex partners ( $p 6 m$ ) & 15 & $4-30$ & 5 & $2-10$ & 1.03 & $1.02,1.04$ \\
\hline No. female sex partners (p6m) & 0 & $0-0$ & 0 & $0-0$ & 1.92 & $1.26,2.93$ \\
\hline
\end{tabular}

${ }^{A}$ Dichotomous yes/no variable.

OR, odds ratio; $\mathrm{Cl}$, confidence interval; Ref, reference; $6 \mathrm{~m}$, past 6 months; CAS, condomless anal sex; EDD, erectile dysfunction drugs; AUDIT, Alcohol Use Disorder Test.

drugs, or other goods for sex, or having received money for escort or sex work) were more likely to report psychosocial stressors, including younger age, bisexual or 'other' self-identity, annual income $<\$ 30000 \mathrm{CAD}$ (the mean Canadian income in 2018 was $\$ 44700^{26}$ ), and to be unstably housed. They were also more likely to report greater sexual escape motivation, loneliness, and anxious symptoms, but less likely to report depressive symptoms. GBM who reported transactional sex were more likely to use some substances, specifically those which are typically used in sexualised situations (i.e. crystal methamphetamine, poppers, GHB, and non-steroid injection drug use), and to engage in behaviours associated with higher risk of HIV and STI transmission (i.e. having more sexual partners, attending sex parties, and having CAS with serodifferent or unknown HIV status partners). However, despite increased sexual risk behaviour, we found that those who engaged in transactional sex were no more likely to be living with HIV, to report a recent gonorrhoea, chlamydia, or syphilis diagnoses, or to use a variety of HIV-prevention strategies including condoms, asking about a partner's HIV status, sero-positioning, sero-sorting, or viral-load sorting. GBM who reported transactional sex were, however, more likely to report using withdrawal as an HIV prevention strategy.

Consistent with the findings of the current analysis, compared to GBM in general, those who engage in transactional sex have been shown to also report higher rates of lifetime and recent drug use, including crystal methamphetamine, poppers, and GHB. ${ }^{27,28}$ Among GBM in Vancouver, previous research found associations between sex work and substance use, such as poppers, injection drugs, cocaine, and heroin. ${ }^{16}$ Findings on specific drug use and transactional sex have been mixed, with some studies showing transactional sex to be associated with injection drug use, as well as cocaine and/or crack cocaine use, but not methamphetamine. ${ }^{29,30}$ The use of substances among GBM who engage in transactional sex is likely to have complex and interrelated motivations and consequences. Substances may be used as a coping mechanism to manage ongoing stressors such as marginalisation due to multiple and intersecting stigmatised identities and behaviours, including transactional sex itself. Substances may also facilitate engaging in transactional sex, as suggested by the finding in this study that those engaging in transactional sex also reported greater escape motivation.
However, the use of substances may lead to decreased inhibitions and participation in sexual behaviours which are associated with higher levels of STI and HIV transmission. ${ }^{31}$ As such, a syndemic approach ${ }^{10,15}$ is needed in order to better understand and support the needs of those who report polysubstance use and/or chemsex and also engage in transactional sex.

Previous research has indicated that men who engage in transactional sex are more likely to be living with HIV ${ }^{16,27,28}$ and are more likely report having more sex partners, including more CAS partners. ${ }^{14,16,27,29,32}$ In the present study, we did not find an independent association between HIV status and transactional sex, highlighting the importance of considering other contributing factors that are associated with both transactional sex and likelihood of living with HIV. For instance, consistent with past research, participants in this study who reported transactional sex were more likely to report more sex partners, more CAS with serodifferent or unknown HIV status partners, and were more likely to participate in group sex parties. Of note, when considering behavioural HIV prevention strategies, we found that those who engaged in transactional sex were equally as likely as those who did not to report always using condoms, sero-positioning, sero-sorting, viral load sorting, anal sex avoidance, and asking the HIV status of their sex partners. However, those who engaged in transactional sex were more likely to report using withdrawal as an HIV prevention strategy.

Given advances in biomedical HIV prevention strategies such as Treatment as Prevention, $\mathrm{U}=\mathrm{U}$, and pre-exposure prophylaxis (PrEP) since the beginning of our study, subsequent changes in sexual behaviour, including decreased condom use, are likely. ${ }^{33,34}$ PrEP, specifically, has been freely available since January 2018 for anyone who needs it through the government of British Columbia, and HIV-negative GBM who engage in transactional sex are likely to be indicated for PrEP due to increased sexual and substance-related behavioural risk. Therefore, greater outreach to increase awareness of biomedical HIV-prevention methods among GBM who engage in transactional sex is warranted. Among GBM living with HIV in Vancouver, previous analysis of the Momentum cohort has shown that rates of viral suppression surpass $95 \%{ }^{35,36}$ Although the risk of HIV transmission is low, risk of STI transmission remains and STI incidence has 
Table 2. Multivariable generalised linear mixed model for engaging in transactional sex (past 6 months).

\begin{tabular}{|c|c|c|c|}
\hline \multicolumn{4}{|l|}{ Transactional sex vs no transactional sex } \\
\hline & aOR & \multicolumn{2}{|c|}{$95 \% \mathrm{Cl}$} \\
\hline Demographic variables & & & \\
\hline \multicolumn{4}{|l|}{ Age (years) } \\
\hline$<30$ & Ref & & \\
\hline $30-44$ & 0.27 & 0.13 & 0.54 \\
\hline$\geq 45$ & 0.09 & 0.03 & 0.22 \\
\hline \multicolumn{4}{|l|}{ Annual income (CAD) } \\
\hline$<\$ 30000$ & Ref & & \\
\hline$\geq \$ 30000$ & 0.56 & 0.32 & 0.99 \\
\hline \multicolumn{4}{|l|}{ Education } \\
\hline$\leq$ High school & Ref & & \\
\hline$>$ High school & 0.30 & 0.13 & 0.70 \\
\hline \multicolumn{4}{|l|}{ Sexual identity } \\
\hline Gay & Ref & & \\
\hline Bisexual/other & 2.38 & 1.21 & 4.69 \\
\hline \multicolumn{4}{|l|}{ Race/ethnicity } \\
\hline White & Ref & & \\
\hline Asian & 0.54 & 0.18 & 1.67 \\
\hline Indigenous & 5.27 & 1.34 & 20.80 \\
\hline Latino/other & 0.89 & 0.25 & 3.21 \\
\hline Stable housing ${ }^{\mathrm{A}}$ & 0.39 & 0.19 & 0.82 \\
\hline \multicolumn{4}{|l|}{ Sexual behaviours (p6m) } \\
\hline Use internet sites to seek sex ${ }^{A}$ & 3.36 & 1.77 & 6.00 \\
\hline Use chat lines to seek sex ${ }^{A}$ & 2.61 & 0.95 & 7.18 \\
\hline Attended sex parties ${ }^{A}$ & 3.65 & 2.14 & 6.22 \\
\hline CAS with serodifferent/unknown partner ${ }^{A}$ & 1.83 & 1.03 & 3.26 \\
\hline \multicolumn{4}{|l|}{ Anal sex role preference } \\
\hline Bottom & Ref & & \\
\hline Versatile & 1.91 & 0.95 & 3.83 \\
\hline Top & 1.23 & 0.58 & 2.58 \\
\hline No anal & 0.36 & 0.09 & 1.42 \\
\hline \multicolumn{4}{|l|}{ HIV prevention strategies ( $\mathrm{p} 6 \mathrm{~m})$} \\
\hline Withdrawal ${ }^{\mathrm{A}}$ & 1.79 & 1.003 & 3.20 \\
\hline \multicolumn{4}{|l|}{ Substance use (p6m) } \\
\hline Crystal methamphetamine $\mathrm{A}^{\mathrm{A}}$ & 4.57 & 2.23 & 9.39 \\
\hline Poppers ${ }^{A}$ & 2.53 & 1.39 & 4.60 \\
\hline Gamma-hydroxybutyric acid ${ }^{A}$ & 2.14 & 1.15 & 4.00 \\
\hline Non-steroid injection drug use $\mathrm{A}^{\mathrm{A}}$ & 3.26 & 1.15 & 9.29 \\
\hline \multicolumn{4}{|l|}{ Continuous psychosocial variables } \\
\hline Cognitive escape scale & 1.06 & 1.01 & 1.10 \\
\hline Loneliness scale & 1.19 & 1.02 & 1.39 \\
\hline HADS anxiety & 1.08 & 1.001 & 1.17 \\
\hline HADS depression & 0.89 & 0.81 & 0.97 \\
\hline
\end{tabular}

(Continued on next page)
Table 2. (Continued).

\begin{tabular}{|c|c|c|c|}
\hline \multicolumn{4}{|c|}{ Transactional sex vs no transactional sex } \\
\hline & aOR & \multicolumn{2}{|c|}{$95 \% \mathrm{Cl}$} \\
\hline No. male sex number & 1.01 & 1.005 & 1.02 \\
\hline No. female sex number & 1.95 & 1.35 & 2.85 \\
\hline
\end{tabular}

${ }^{A}$ Dichotomous yes/no variable.

p6m, past 6 months; CAS, condomless anal sex; HADS, Hospital Anxiety and Depression Scale.

been increasing. ${ }^{1,37}$ Thus, regular and effective STI screening, treatment, and prevention which is inclusive of, but limited not to, condom use and the use of biomedical prevention strategies, needs to be continuously encouraged and promoted among GBM, particularly those who engage in transactional sex.

Exploring psychosocial factors, we found that reporting higher cognitive escape, loneliness, and anxious symptoms were associated with greater odds of engaging in transactional sex, whereas greater depressive symptoms were associated with lower odds. This suggests that some of these men may be experiencing challenging life situations in which they may feel unsafe or unsupported. Consequently, they may benefit from increased support services through government or community agencies, as well as from an increase in peer support specifically. These findings bring nuance to the complexity of mental health experiences and highlight a difference between loneliness (which may be a precursor to depression) and depression. ${ }^{38}$ In previous research, there have been mixed findings as to the relationships between depression and higher risk sexual behaviours. ${ }^{39}$ A longitudinal analysis of 4295 HIV-negative GBM found depression to have a U-shaped relationship with higher risk sexual behaviour such that those with moderate levels of depression engaged in higher risk behaviours than those with fewer or greater depressive symptoms. ${ }^{40}$ Further, although Alvy et al. (2011) found a positive relationship between depressive symptoms and HIV transmission risk (defined as CAS with a serodifferent or unknown HIV-status partner), they also found that cognitive escape partially mediated this relationship. ${ }^{39}$ As such, our findings further illustrate that the specific relationships between psychosocial variables and transactional sex are complex and give further support to the importance of considering transactional sex within a syndemic framework.

This study has several limitations. As with all self-report studies, this study is subject to interpretation bias. For example, we did not define what was meant by 'goods' and this may have been interpreted differently by different participants. However, given our use of multiple measures to assess engagement in transactional sex, we believe that we have mitigated this bias and ultimately, exchanging any form of 'goods' for sex could still be classified as transactional sex. 
Further, the open nature of our categorisation of transactional sex may have allowed us to capture a wider range of transactional sex behaviours than is typically considered. Second, our study began prior to the approval and widespread use of PrEP in Canada. Consequently, some of the participants had already completed the study before PrEP was made freely available and we were therefore unable to include PrEP use in the analysis. An additional limitation of this study is due to the small proportion of participants who reported transactional sex in general, and giving drugs, goods, or money in exchange for sex, specifically. Consequently, we were unable to explore further nuances of transactional sex, such as differences in those who report receiving drugs or goods for sex as compared to those who receive money for sex, or potential differences between those who buy sex compared with those who sell sex. ${ }^{14,27}$ However, as these analyses are beyond the focus of the current study, we recommend further research that can tease apart these nuances and separates those who only buy, those who only sell, and those who do both, as meaningful similarities and differences have been noted. ${ }^{13}$

\section{Conclusion}

This study explored multi-level factors associated with transactional sex among GBM in Vancouver, Canada. Based on our findings, structural support, which uses a holistic approach, may be beneficial for health and social care programs targeted specifically to GBM who engage in transactional sex to better address their specific needs. Using online interventions may be particularly relevant for these men, as they tend to be highly engaged in online environments to seek sex partners. Moreover, stigma associated with sex work and transactional sex may deter them from engaging in in-person community services. ${ }^{8}$ One such example of a virtual intervention is Get Checked Online, an online tool supported by the BC Centre for Disease Control to enable online testing for STIs in an easy and convenient manner. ${ }^{41}$

Furthermore, given the significant associations reported above between substance use and transactional sex, we support substance use intervention programs aimed at reducing problematic substance use behaviours and recommend programs specifically for GBM who also engage in transactional sex. ${ }^{42}$

Finally, our findings demonstrate the need for supportive structural interventions such as increased housing stability and access to alternative occupational and educational programs for GBM who engage in transactional sex. Given the complexity of the motivations for and outcomes associated with transactional sex, a syndemic approach that considers the multifaceted and interrelated nature of transactional sex, substance use, sexual behaviour, and psychological functioning is recommend for supportive programming and future research.

\section{References}

1 BC Centre for Disease Control. STI annual report 2017. BC Ministry of Health; 2018.

2 Haddad N, Weeks A, Robert A, Totten S. HIV in Canada - surveillance report, 2019. Can Commun Dis Rep. 2021; 47(1): 77-86. doi:10.14745/ccdr.v47i01a11.

3 Moore DM, Cui Z, Lachowsky N, Raymond HF, Roth E, Rich A, Sereda P, Howard T, McFarland W, Lal A, Montaner J, Corneil T, Hogg RS. HIV community viral load and factors associated with elevated viremia among a community-based sample of men who have sex with men (MSM) in Vancouver, Canada. $J$ Acquir Immune Defic Syndr 2016; 72(1): 87-95. doi:10.1097/QAI.0000000000000934

4 Javanbakht M, Ragsdale A, Shoptaw S, Gorbach PM. Transactional sex among men who have sex with men: differences by substance use and HIV status. J Urban Health 2019; 96(3): 429-41. doi:10.1007/ s11524-018-0309-8

5 Oldenburg CE, Perez-Brumer AG, Reisner SL, Mimiaga MJ. Transactional sex and the HIV epidemic among men who have sex with men (MSM): results from a systematic review and metaanalysis. AIDS Behav 2015; 19(12): 2177-83. doi:10.1007/ s10461-015-1010-5

6 Ott MQ, Bärnighausen T, Tanser F, Lurie MN, Newell M-L. Age-gaps in sexual partnerships: seeing beyond 'sugar daddies'. AIDS 2011; 25(6): 861-3. doi:10.1097/QAD.0b013e32834344c9

7 McCarthy B, Benoit C, Jansson M, Kolar K. Regulating sex work: heterogeneity in legal strategies. Annu Rev Law Soc Sci 2012; 8: 255-71. doi:10.1146/annurev-lawsocsci-102811-173915

8 Baral SD, Friedman MR, Geibel S, Rebe K, Bozhinov B, Diouf D, Sabin $\mathrm{K}$, Holland CE, Chan R, Cáceres CF. Male sex workers: practices, contexts, and vulnerabilities for HIV acquisition and transmission. Lancet 2015; 385(9964): 260-73. doi:10.1016/S0140-6736(14) 60801-1

9 Benoit C, Smith M, Jansson M, Healey P, Magnuson D. 'The prostitution problem': claims, evidence, and policy outcomes. Arch Sex Behav 2019; 48(7): 1905-23. doi:10.1007/s10508-018-1276-6

10 Alvarado BE, Mueses HF, Galindo J, Martínez-Cajas JL. Application of the 'syndemics' theory to explain unprotected sex and transactional sex: A cross-sectional study in men who have sex with men (MSM), transgender women, and non-MSM in Colombia. Biomédica 2020; 40(2): 391-403. doi:10.7705/biomedica.5082

11 Bauermeister JA, Eaton L, Meanley S, Pingel ES, On Behalf of the UHIP Partnership. Transactional sex with regular and casual partners among young men who have sex with men in the Detroit metro area. Am J Mens Health 2017; 11(3): 498-507. doi:10.1177/ 1557988315609110

12 Berg RC, Weatherburn P, Marcus U, Schmidt AJ. Links between transactional sex and HIV/STI-risk and substance use among a large sample of European men who have sex with men. BMC Infect Dis 2019; 19(1): 686. doi:10.1186/s12879-019-4326-3

13 Bond KT, Yoon IS, Houang ST, Downing Jr MJ, Grov C, Hirshfield S. Transactional sex, substance use, and sexual risk: comparing pay direction for an internet-based US sample of men who have sex with men. Sex Res Social Policy 2019; 16(3): 255-67. doi:10.1007/ s13178-018-0366-5

14 Nerlander LM, Hess KL, Sionean C, Rose CE, Thorson A, Broz D, PazBailey G. Exchange sex and HIV infection among men who have sex with men: 20 US cities, 2011. AIDS Behav 2017; 21(8): 2283-94. doi:10.1007/s10461-016-1450-6

15 Walters SM, Braksmajer A, Coston B, Yoon I, Grov C, Downing Jr MJ, Teran R, Hirshfield S. A syndemic model of exchange sex among HIVpositive men who have sex with men. Arch Sex Behav 2020; 49(6): 1965-1978. doi:10.1007/s10508-020-01628-8

16 Weber AE, Craib KJ, Chan K, Martindale S, Miller ML, Schechter MT, Hogg RS. Sex trade involvement and rates of human immunodeficiency virus positivity among young gay and bisexual 
men. Int $J$ Epidemiol 2001; 30(6): 1449-54. doi:10.1093/ije/30.6. 1449

17 Earls CM, David H. A psychosocial study of male prostitution. Arch Sex Behav 1989; 18(5): 401-19. doi:10.1007/BF01541972

18 Argento E, Taylor M, Jollimore J, Taylor C, Jennex J, Krusi A, Shannon K. The loss of Boystown and transition to online sex work: strategies and barriers to increase safety among men sex workers and clients of men. Am J Mens Health 2018; 12(6): 1994-2005. doi:10.1177/1557988316655785

19 Gile KJ, Handcock MS. Respondent-driven sampling: an assessment of current methodology. Sociol Methodol 2010; 40(1): 285-327. doi:10.1111/j.1467-9531.2010.01223.x

20 Saunders JB, Aasland OG, Babor TF, de la Fuente JR, Grant M. Development of the alcohol use disorders identification test (AUDIT): WHO collaborative project on early detection of persons with harmful alcohol consumption-II. Addiction 1993; 88(6): 791804. doi:10.1111/j.1360-0443.1993.tb02093.x

21 Kalichman SC, Rompa D. Sexual sensation seeking and sexual compulsivity scales: validity, and predicting HIV risk behavior. J Pers Assess 1995; 65(3): 586-601. doi:10.1207/s15327752 jpa6503_16

22 McKirnan DJ, Vanable PA, Ostrow DG, Hope B. Expectancies of sexual 'escape' and sexual risk among drug-and alcohol-involved gay and bisexual men. $J$ Subst Abuse 2001; 13(1-2): 137-54. doi:10.1016/S0899-3289(01)00063-3

23 Gierveld JDJ, Tilburg TV. A 6-item scale for overall, emotional, and social loneliness: Confirmatory tests on survey data. Res Aging 2006; 28(5): 582-98. doi:10.1177/0164027506289723

24 Snaith RP. The hospital anxiety and depression scale. Health Qual Life Outcomes 2003; 1(1): 29. doi:10.1186/1477-7525-1-29

25 Lima VD, Geller J, Bangsberg DR, Patterson TL, Daniel M, Kerr T, Montaner JSG, Hogg RS. The effect of adherence on the association between depressive symptoms and mortality among HIV-infected individuals first initiating HAART. AIDS 2007; 21(9): 1175-83. doi:10.1097/QAD.0b013e32811ebf57

26 Statistics Canada. Table 11-10-0191-01. Income statistics by economic family type and income source. Statistics Canada; 2021. doi:10.25318/1110019101-eng

27 Koken JA, Parsons JT, Severino J, Bimbi DS. Exploring commercial sex encounters in an urban community sample of gay and bisexual men: a preliminary report. $J$ Psychol Human Sex 2005; 17(1-2), 197-213. doi:10.1300/J056v17n01_12

28 Yu G, Goldsamt LA, Clatts MC, Giang LM. Sexual initiation and complex recent polydrug use patterns among male sex workers in Vietnam: a preliminary epidemiological trajectory. Arch Sex Behav 2016; 45(4): 975-81. doi:10.1007/s10508-015-0667-1

29 Kuyper LM, Lampinen TM, Li K, Spittal PM, Hogg RS, Schechter MT, Wood E. Factors associated with sex trade involvement among male participants in a prospective study of injection drug users. Sex Transm Infect 2004; 80(6): 531-535. doi:10.1136/sti.2004.011106

30 Newman PA, Rhodes F, Weiss RE. Correlates of sex trading among drug-using men who have sex with men. Am J Public Health 2004; 94(11): 1998-2003. doi:10.2105/AJPH.94.11.1998

31 Tan RKJ, O'Hara CA, Koh WL, Le D, Tan A, Tyler A, Tan C, Kwok C, Banerjee S, Wong ML. Delineating patterns of sexualized substance use and its association with sexual and mental health outcomes among young gay, bisexual and other men who have sex with men in Singapore: a latent class analysis. BMC Public Health 2021; 21(1): 1026. doi:10.1186/s12889-021-11056-5

32 Mimiaga MJ, Reisner SL, Tinsley JP, Mayer KH, Safren SA. Street workers and internet escorts: contextual and psychosocial factors surrounding HIV risk behavior among men who engage in sex work with other men. $J$ Urban Health 2009; 86(1): 54-66. doi:10.1007/ s11524-008-9316-5

33 Chen Y-H, Guigayoma J, McFarland W, Snowden JM, Raymond HF. Increases in pre-exposure prophylaxis use and decreases in condom use: Behavioral patterns among HIV-negative San Francisco men who have sex with men, 2004-2017. AIDS Behav 2019; 23(7): 1841-5. doi:10.1007/s10461-018-2299-7

34 Montaño MA, Dombrowski JC, Dasgupta S, Golden MR, Duerr A, Manhart LE, Barbee LA, Khosropour CM. Changes in sexual behavior and STI diagnoses among MSM initiating PrEP in a clinic setting. AIDS Behav 2019; 23(2): 548-55. doi:10.1007/s10461018-2252-9

35 Armstrong HL, Gitelman J, Cui Z, Bacani N, Sereda P, Lachowsky NJ, Card KG, Raymond HF, Montaner J, Hogg RS, Roth EA, Hull M, Howard T, McFarland W, Moore DM. Recent decreases in unsuppressed viral load among HIV-positive men who have sex with men in Vancouver, Canada from 2012-2017. In 'International AIDS Conference, 2018 July'.

36 Moore DM, Cui Z, Lachowsky NJ, Rich AJ, Roth EA, Raymond HF, Sereda P, Montaner J, Wong J, Armstrong HL, Hall D, Hogg RS, and the Momentum Study Team. Increasing HIV treatment optimism but no changes in HIV risk behavior among men who have sex with men in Vancouver, Canada. J Acquir Immune Defic Syndr 2017; 76(4): e98-101. doi:10.1097/QAI.0000000000001542

37 Public Health Agency of Canada (PHAC). Report on sexually transmitted Infections in Canada, 2017. Ottawa, Ontario, Canada: PHAC; 2019.

38 Spithoven AWM, Lodder GMA, Goossens L, Bijttebier P, Bastin M, Verhagen M, Scholte RHJ. Adolescents' loneliness and depression associated with friendship experiences and well-being: a personcentered approach. $J$ Youth Adolesc 2017; 46(2): 429-41. doi:10.1007/ s10964-016-0478-2

39 Alvy LM, McKirnan DJ, Mansergh G, Koblin B, Colfax GN, Flores SA, Hudson S, Project MIX Study Group. Depression is associated with sexual risk among men who have sex with men, but is mediated by cognitive escape and self-efficacy. AIDS Behav 2011; 15(6): 1171-9. doi:10.1007/s10461-010-9678-Z

40 Koblin BA, Husnik MJ, Colfax G, Huang Y, Madison M, Mayer K, Barresi PJ, Coates TJ, Chesney MA, Buchbinder S. Risk factors for HIV infection among men who have sex with men. AIDS 2006; 20(5): 731-9. doi:10.1097/01.aids.0000216374.61442.55

41 Falasinnu T, Gustafson P, Gilbert M, Shoveller J. Risk prediction in sexual health contexts: Protocol. JMIR Res Protoc 2013; 2(2): e57. doi:10.2196/resprot.2971

42 Kenyon C, Wouters K, Platteau T, Buyze J, Florence E. Increases in condomless chemsex associated with HIV acquisition in MSM but not heterosexuals attending a HIV testing center in Antwerp, Belgium. AIDS Res Ther 2018; 15(1): 14. doi:10.1186/s12981018-0201-3 
Data availability. The data that support this study cannot be publicly shared due to ethical or privacy reasons and may be shared upon reasonable request to the corresponding author if appropriate.

Conflicts of interest. Heather Armstrong is a Joint Editor of Sexual Health, but was blinded from the peer-review process for this paper.

Declaration of funding. This work was supported by the National Institute on Drug Abuse (R0IDA03I055-0IAI) and the Canadian Institutes of Health Research (MOP-107544, FDN-143342, PJT-153139). NJL was supported by a CANFAR/CTN Postdoctoral Fellowship Award. HLA was supported by a Postdoctoral Fellowship award from the Canadian Institutes of Health Research (Grant \#MFE-I52443). DMM and NJL are supported by a Michael Smith Foundation for Health Research Scholar Awards (\#5209, \#16863). KGC is supported by a Canadian Institutes of Health Research Health Systems Impact Fellowship award, a Michael Smith Foundation for Health Research Trainee award, and a Canadian HIV Trials Network/Canadian Foundation for AIDS Research Postdoctoral Fellowship award. JMS is supported by a CTN postdoctoral fellowship award and a Michael Smith Foundation for Health Research trainee award.

Acknowledgements. We thank the Momentum Study participants, office staff and community advisory board, as well as our community partners: Health Initiative for Men, YouthCO HIV \& Hep C Society, and Positive Living Society of BC.

Author affiliations

AUniversity of Southampton, Southampton SOI7 IBJ, UK.

${ }^{B}$ British Columbia Centre for Excellence in HIVIAIDS, Vancouver, BC, Canada.

CUniversity of British Columbia, Vancouver, BC, Canada.

DUniversity of Victoria, Victoria, BC, Canada.

ESimon Fraser University, Burnaby, BC, Canada. 